\title{
Intracellular Expression of Single-Chain Variable Fragments To Inhibit Early Stages of the Viral Life Cycle by Targeting Human Immunodeficiency Virus Type 1 Integrase
}

\author{
PNINA LEVY-MINTZ, ${ }^{1}$ LINGXUN DUAN, ${ }^{1}$ HUIZHONG ZHANG,${ }^{1}$ BAOCHENG HU, ${ }^{1}$ \\ GEETHANJALI DORNADULA, ${ }^{1}$ MINGHUA ZHU,${ }^{1}$ JOSEPH KULKOSKY,${ }^{1}$ \\ DIANE BIZUB-BENDER, ${ }^{2}$ ANNA MARIE SKALKA, ${ }^{2}$ \\ AND ROGER J. POMERANTZ ${ }^{1 *}$ \\ Dorrance H. Hamilton Laboratories, Center for Human Virology, Division of Infectious Diseases, \\ Department of Medicine, Jefferson Medical College, Thomas Jefferson University, Philadelphia, \\ Pennsylvania 19107, ${ }^{1}$ and Fox Chase Cancer Center, Philadelphia, Pennsylvania $19111^{2}$
}

Received 10 July 1996/Accepted 10 September 1996

\begin{abstract}
Integration of viral DNA into a chromosome of the infected host cell is required for efficient replication of a retroviral genome, and this reaction is mediated by the virus-encoded enzyme integrase (IN). As IN plays a pivotal role in establishing infection during the early stages of the retroviral life cycle, it is an attractive target for therapeutic intervention. However, the lack of effective antiviral drug therapy against this enzyme has led to the testing of other novel approaches towards its inhibition. In these studies, a panel of anti-human immunodeficiency virus type 1 (anti-HIV-1) IN hybridomas has been used in the construction of single-chain variable antibody fragments (SFvs). The monoclonal antibodies produced by these hybridomas, and derived SFvs, bind to different domains within IN. We now demonstrate that intracellular expression of SFvs which bind to IN catalytic and carboxy-terminal domains results in resistance to productive HIV-1 infection. This inhibition of HIV-1 replication is observed with SFvs localized in either the cytoplasmic or nuclear compartment of the cell. The expression of anti-IN SFvs in human T-lymphocytic cells and peripheral blood mononuclear cells appears to specifically neutralize IN activity prior to integration and, thus, has an effect on the integration process itself. These data support our previous studies with an anti-HIV-1 reverse transcriptase SFv and demonstrate further that intracellularly expressed SFvs can gain access to viral proteins of the HIV-1 preintegration complex. This panel of anti-HIV-1 IN SFvs also provides the tools with which to dissect the molecular mechanism(s) directly involved in integration within HIV-1-infected cells.
\end{abstract}

An early event in the life cycle of all retroviruses, including human immunodeficiency virus type 1 (HIV-1), is integration of a double-stranded DNA copy of the viral genome into chromosomal DNA of the host cells. This step is necessary for productive viral replication (37). Genetic analyses have shown that the integrase-encoding region, located at the $3^{\prime}$ end of the pol gene, and sequences at the termini of retroviral DNA are required for this reaction (37).

Soon after infection, retroviral DNA and proteins are found within a subviral nucleoprotein complex in the cytoplasm of infected cells $(8,25)$. In vitro, these isolated complexes can accomplish integration of viral DNA into an exogenous target molecule $(8,28)$. In a natural infection, linear viral DNA contained within preintegration complexes has been shown to be the direct precursor of proviral DNA. When integrase (IN) function is abrogated by site-specific mutagenesis, newly synthesized viral DNA cannot be integrated. Instead, intracellular accumulation of viral DNA with joined ends, producing a tandem arrangement of the viral long terminal repeat sequences (2-LTR), is observed $(10,26)$.

Analysis of IN activity in vitro has demonstrated that this viral product is the only protein required for integration (16, $30,36)$. The integration reaction, as defined by in vitro studies,

\footnotetext{
* Corresponding author. Mailing address: Dorrance H. Hamilton Laboratories, Center for Human Virology, Division of Infectious Diseases, Department of Medicine, Jefferson Medical College, Thomas Jefferson University, 1020 Locust St., Suite 329, Philadelphia, PA 19107. Phone: (215) 503-8575. Fax: (215) 923-1956.
}

proceeds in two critical steps. The first step (processing) is integrase-dependent cleavage of two nucleotides from the $3^{\prime}$ end of each strand of viral DNA. The next step (joining) is a concerted cleavage and ligation reaction. In this step, a staggered cut is generated in the target DNA by nucleophilic attack involving the hydroxyl group present at the recessed $3^{\prime}$ ends of viral DNA, which then becomes linked to the $5^{\prime}$ ends of the target DNA at the cleavage site $(28,41,59,62)$. The resulting gaps in the target DNA are repaired, likely by host enzymes, to create short direct repeats flanking the provirus, a hallmark of all retroviral integration reactions $(37,41)$.

Although it has been over a decade since the discovery of HIV-1 as the etiologic agent of AIDS, there has been modest progress in the development of adequate therapy to stop or significantly alter the ultimately fatal course of the infection (33). Such a course leads to severe immunodeficiency in most infected individuals, specifically by depleting CD $4^{+} \mathrm{T}$ lymphocytes, which appear to be the major viral reservoirs present in lymphoid organs and in the peripheral blood (42a).

As IN plays a key role in the early stages of the retroviral life cycle, this protein has become a very attractive target for specific therapy against HIV-1. Analysis of the integrase reaction in vitro has demonstrated that HIV-1 IN protein can be segregated into several functional domains (27). The amino terminus of IN possesses zinc finger homology. The central core domain harbors catalytic activity and is characterized by the presence of three invariant acidic residues (D, D-35, E) (39). Finally, a less conserved carboxy-terminal domain may be involved in dimerization of IN, as well as providing a nonspecific 
DNA binding activity $(3,27,35)$. Collectively, the integrity of these domains is important for precise and efficient integration of retroviral DNA into the host cell's genome (37). Traditionally, antiviral approaches have been aimed at limiting lentiviral replication. Although HIV-1 IN is conceptually an ideal target for inhibition of HIV-1 replication, unlike HIV-1 reverse transcriptase (RT), there are only a few reported compounds which inhibit HIV-1 IN $(12,13,52)$. Currently, antiviral therapies based on RT inhibitors, protease inhibitors, cytokines, and receptor blocking agents are not completely successful. This is due to the ability of HIV-1 to mutate, which results in rapid development of numerous variants, some of which can evade host defenses or become resistant to various antiviral agents $(29,64)$. However, an alternative approach, antiviral gene therapy, in which host cells may be genetically altered or engineered to confer long-lasting protection against viral infection or replication, appears to be an attractive and convincing technology $(18,58)$. Several such strategies are currently being reported and applied towards the inhibition of HIV-1 replication or the elimination of the infected cells. They include exploitation of trans-dominant-negative mutant HIV-1 protein expression, viral antisense oligonucleotide sequences, specific ribozymes, and HIV-1 trans-activated suicide genes $(15,44,45,66,69)$.

Recently, several reports described the successful use of an intracellular immunization strategy, targeted against HIV-1 replication, which involved the expression of recombinant genes encoding antibody fragments within cells (19-23, 47, 49, 61). Advances in the design and engineering of single-chain antigen binding proteins promise increased utility of such recombinant antibody genes $(21,67)$. The single-chain variable fragment $(\mathrm{SFv})$ of an antibody is the smallest structural domain which retains the complete specificity and binding site capabilities of the parental antibody. Intracellular expression of SFv constructs and the synthesis of single-chain antibodies in cells have been reported to alter or block various steps in mammalian cell growth and can be used to understand the normal, as well as pathological, cellular processes (7).

Recently, we have reported that intracellular expression of SFv moieties targeted to the HIV-1 regulatory protein Rev and RT potently inhibited HIV-1 replication in human cells (19-23, $58,61,68)$. Rev is pivotal to the life cycle of HIV-1 after integration of viral DNA into the host genome, functioning to establish the provirus and acting by rescuing unspliced viral RNA from the nuclei of HIV-1-infected cells (17). The data generated from our anti-HIV-1 RT SFv studies indicate that the preintegration complex can be targeted by using proteinbased gene therapeutic strategies (61). To further expand intracellular immunization as a tool for gene therapy in the treatment of HIV-1 infections, IN of HIV-1 was targeted for specific blockade by intracellular SFv expression in order to halt HIV-1 replication prior to integration. We now report the construction of a panel of complete SFvs from murine hybridomas producing anti-HIV-1 IN immunoglobulin $\mathrm{G}$ ( $\mathrm{IgG}$ ) (43). The IN enzyme of HIV-1 was also chosen as a target for SFv-induced inhibition in order to study the early stages of HIV-1 replication, prior to the establishment of the provirus. If such a step can be blocked successfully, viral replication in human cells should be halted. In addition, inhibition of HIV-1 IN by SFvs that are preferentially expressed in different cellular compartments would also provide some clues as to how IN may function within the HIV-1 preintegration complex and how it may interact with host cell factors to accomplish integration with marked efficiency and specificity.

\section{MATERIALS AND METHODS}

Construction of anti-IN SFvs. The five murine hybridoma cell lines used in these studies, which produce monoclonal antibodies (MAbs) against HIV-1 IN have been described previously (6). The immunogen used to generate these anti-IN MAbs was the bacteria-expressed recombinant HIV-1 IN protein. The hybridoma cells were grown in RPMI 1640 medium supplemented with $10 \%$ fetal calf serum (FCS) after the hybridomas were transduced with a retroviral vector that expresses a murine abVк ribozyme, as described previously (20). Approximately $2 \times 10^{7}$ cells were used for preparation of total cellular RNA by lysis with guanidinium isothiocyanate buffer and a cesium chloride gradient procedure, as previously described (4). Culture supernatants containing IN MAbs were used in the in vitro IN antigen binding assays, as described previously (6).

The cDNAs of the variable heavy chain $\left(\mathrm{V}_{\mathrm{H}}\right)$ and light chain $\left(\mathrm{V}_{\mathrm{L}}\right)$ regions of anti-HIV-1 IN monoclonal IgG transcripts were synthesized by RT-initiated PCR (RT PCR) $(4,19)$. Primer sets used to amplify murine variable-region heavy and light chains (Ig-Primer Methodology) were obtained from Novagen (Madison, Wis.). For first-strand cDNA synthesis, $5 \mu \mathrm{g}$ of total RNA was mixed with the $3^{\prime}$ primers (antisense) specific for $\mathrm{V}_{\mathrm{L}}$ or $\mathrm{V}_{\mathrm{H}}$ regions, heated for $5 \mathrm{~min}$ at $65^{\circ} \mathrm{C}$, and then incubated at $37^{\circ} \mathrm{C}$ for $1 \mathrm{~h}$ with $200 \mathrm{U}$ of avian myeloblastosis virus RT in a buffer containing $0.07 \mathrm{M} \mathrm{KCl}, 0.02 \mathrm{M}$ Tris $(\mathrm{pH} 8.3), 5 \mathrm{mM}$ dithiothreitol, and $1.0 \mu \mathrm{M}$ (each) deoxynucleoside triphosphate (dNTP) in a $10-\mu$ l volume. After reverse transcription, $5 \mu \mathrm{l}$ of template cDNA was subjected to PCR amplification, using the appropriate primers (Novagen) along with $0.5 \mu \mathrm{l}$ of Taq polymerase (Perkin-Elmer Corp., Norwalk, Conn.) in PCR buffer containing $2.5 \mathrm{mM}$ $\mathrm{MgCl}_{2}$ in a $50-\mu \mathrm{l}$ total volume. Amplification was carried out in a thermal cycler (Perkin-Elmer Corp.) for 1 cycle of denaturation at $94^{\circ} \mathrm{C}$ for $5 \mathrm{~min}$ and then for 35 cycles with the following parameters: denaturation for $1 \mathrm{~min}$ at $94^{\circ} \mathrm{C}$, annealing for $90 \mathrm{~s}$ at $50^{\circ} \mathrm{C}$, and extension for $60 \mathrm{~s}$ at $72^{\circ} \mathrm{C}$, with a final extension of 10 min. Each of the PCR-amplified fragments was cloned into the pT7 Blue (R) vector (Novagen) (50). Clones were first screened by PCR amplification, using primers specific to the pT7 polylinker for the correct size, and analyzed further by DNA sequencing. PCR primers $\left(5^{\prime}\right.$ and $3^{\prime}$ ends) containing appropriate restriction enzyme sites for further cloning were used to reamplify each of the $\mathrm{V}_{\mathrm{L}}$ and $V_{H}$ fragments, with deletion of the remaining secretory leader sequences. The DNAs of light and heavy chains were joined together via a flexible linker, as described by Duan et al. (22). The anti-IN $\mathrm{V}_{\mathrm{L}}$ fragment was cloned via NdeI and $A p a \mathrm{I}$ sites $5^{\prime}$ to the linker, and the anti-IN $\mathrm{V}_{\mathrm{H}}$ was cloned as a $B g l \mathrm{II}-E c o \mathrm{RI}$ fragment $3^{\prime}$ to the linker, to obtain anti-IN SFvs as a single gene construct. As a control SFv, a human anti-hepatitis B virus (anti-HBV) core antigen SFv has been constructed by using the M13-based phage display system (reference 54 and unpublished data).

For construction of SFvs that contain the HIV-1 Tat nuclear localization signal (NLS) (63), the following two oligonucleotides were synthesized: TatS-1 ( $5^{\prime}-\mathrm{CC}$ GAGCTCGGCAGGAAGAAGCGGAGACAGCGACG-3') and TatS-2 (5'-CC AGATCTGTTCTGATGAGCTCTTCGTCGCTGTCTCCGCTTC-3'). The Tat NLS DNA fragment was synthesized by incubating $1 \mu \mathrm{g}$ of each of the oligonucleotides to form a hemiduplex, followed by PCR amplification in a 100- $\mu$ volume containing $10 \mathrm{mM}$ Tris- $\mathrm{HCl}(\mathrm{pH} 8.3), 50 \mathrm{mM} \mathrm{KCl}, 2.5 \mathrm{mM} \mathrm{MgCl}_{2}, 200$ $\mu \mathrm{M}$ (each) dNTP, and $5 \mathrm{U}$ of Taq polymerase. The cycling conditions were as follows: $94^{\circ} \mathrm{C}$ for $1.5 \mathrm{~min}, 50^{\circ} \mathrm{C}$ for $1.5 \mathrm{~min}$, and $72^{\circ} \mathrm{C}$ for $2 \mathrm{~min}$ for 10 cycles. The PCR products were cloned directly in the pT7 Blue (R) vector (Novagen) to generate plasmid pT7 Tat-sig. The 54-bp SacI-BglII DNA fragment was then inserted into pT7IN-SFv33, which was partially digested with $S a c \mathrm{I}$ and $B g l \mathrm{II}$ to generate pT7IN-SFv33/NU.

The murine leukemia virus-based retroviral expression vector PSLXCMV which contains the bacterial neomycin resistance gene (neo), was used in these experiments $(54,60)$. Each of the anti-IN SFv constructs was subcloned as an $M l u \mathrm{I}-X h o \mathrm{I}$ fragment in the MluI-XhoI sites of the polylinker region of pSLX CMV vector. Accurate cloning of all of the DNA of the SFvs in the vector was confirmed by DNA sequencing. The construction and characterization of the pSLXCMV-CAT and pSLXCMV-D8 SFv vector constructs, which express chloramphenicol acetyltransferase (CAT) and an anti-Rev SFv protein, respectively, and which were used as controls in certain experiments, have been described previously (23)

In vitro binding of anti-IN SFvs. Methods for bacterial expression of each of the anti-HIV-1 IN SFvs were reported previously (22). Briefly, during the construction of SFvs, NdeI and Bam HI sites were added to the $5^{\prime}$ and $3^{\prime}$ ends of the SFv cDNA fragments by PCR-based oligonucleotide amplification. The Nde and BamHI SFv fragments were inserted into the pET19b vector (50). Expression of SFvs in Escherichia coli DE21, which carries inducible T7 RNA polymerase (65), has been demonstrated previously (23).

After induction of SFv expression by growth in $1 \mathrm{mM}$ isopropyl- $\beta$-D-thiogalactopyranoside (IPTG) for $4 \mathrm{~h}$, analysis of fractions from lysed cells indicated that the vast majority of recombinant SFv protein was in an insoluble form. For assays of expression of SFvs in E. coli, $5 \mu \mathrm{l}$ of induced bacterial lysate (insoluble fraction) was loaded and separated by $12 \%$ polyacrylamide gel electrophoresis (PAGE) (48). For partial purification of SFv proteins, $\mathrm{Ni}^{2+}$ columns were utilized; the insoluble fraction was dissolved in $6 \mathrm{M}$ urea and applied to the meta chelation affinity resin. Renaturation of the denatured bound protein was accomplished directly on the column by $1 \mathrm{M}$ stepwise reductions in the concen- 
tration of urea in the binding buffer prior to elution with buffer containing 250 $\mathrm{mM}$ imidazole in the absence of urea.

Binding affinities of anti-IN SFvs were determined via enzyme-linked immunosorbent assay (ELISA) after coating of the wells with purified recombinant HIV-1 or avian sarcoma virus (ASV) IN (6). $\mathrm{Ni}^{2+}$ column-purified anti-HIV-1 SFvs and parent murine anti-IN IgGs were diluted at various concentrations, starting at $4 \mu \mathrm{g} / \mathrm{ml}$, and added to the wells for further incubation. After the wells were washed with phosphate-buffered saline (PBS), alkaline phosphatase-conjugated goat anti-mouse antibody was applied for detection (6).

Specificity of anti-IN SFvs was next demonstrated by Western blot (immunoblot) analysis. Total protein from $E$. coli cells induced for the production of HIV-1 IN was separated by PAGE and transferred to a PVD transfer membrane (Dupont Inc.). After being blocked with a 5\% milk-PBS solution, the proteins were probed with either IN MAb33, anti-IN SFv33, or anti-IN SFv4 and then with horseradish peroxidase-conjugated goat anti-mouse $\mathrm{IgG}$, as a secondary antibody, using the ECL system (Amersham Life Science).

Cell cultures. The PA317 amphotropic-retrovirus-packaging cell line was maintained in Dulbecco's modified Eagle's medium (DMEM) supplemented with $10 \%$ FCS (GIBCO-BRL) (54). The same culture conditions were used for NIH 3 T3 cells. SupT1 is a CD4 ${ }^{+}$human T-lymphocytic cell line, susceptible to HIV-1 infection (57), which was grown in RPMI 1640 medium supplemented with $10 \%$ FCS. All the cells were grown at $37^{\circ} \mathrm{C}$ in a humidified incubator with $5 \% \mathrm{CO}_{2}$.

Production of amphotropic retroviruses. Helper-free recombinant murine leukemia virus-based retroviruses were produced by transfection of PA317 packaging cells with recombinant retrovirus vector plasmids. PA317 cells that were approximately 50 to $60 \%$ confluent were transfected in $100-\mathrm{mm}$ dishes with $20 \mu \mathrm{g}$ of the plasmid DNA by a standard calcium phosphate transfection method (Promega, Inc.) and then incubated in DMEM containing 10\% FCS (growth medium) for $14 \mathrm{~h}$. This medium was then removed and replaced with fresh DMEM growth medium. After a 24-h incubation, cells were replated in DMEM growth medium containing G418 (750 $\mu \mathrm{g} / \mathrm{ml}$; Sigma). The medium was changed every 4 days until colonies formed. The G418-resistant colonies were then pooled and grown for two more weeks in medium containing G418.

Transduction of T-lymphocytic cells and human PBMC. For transduction of SupT1 cells, $5 \mathrm{ml}$ of G418-free supernatant containing virions produced by transfected PA317 cells was used to infect $1 \times 10^{6}$ to $2 \times 10^{6}$ target cells, in the presence of polybrene $(4 \mu \mathrm{g} / \mathrm{ml})$, for 24 to $48 \mathrm{~h}$. Cells were then washed with serum-free medium and maintained under G418 selection conditions for 2 weeks. Each of the infected cell populations was cultured in G418-containing medium $(800 \mu \mathrm{g} / \mathrm{ml})$ for 3 weeks.

Human peripheral blood mononuclear cells (PBMC) purified from buffy coats of several HIV-1-seronegative individuals were stimulated with phytohemagglutinin $(5 \mu \mathrm{g} / \mathrm{ml})$ and interleukin-2 $(200 \mathrm{U} / \mathrm{ml})$ for 3 days; then $10^{6}$ PBMC were cultured with $10 \mathrm{ml}$ of supernatant from the indicated SFv-transfected PA317 cultures for 3 days, with daily replacement with fresh supernatant. The transduced PBMC, cultured only in interleukin-2 $(100 \mathrm{U} / \mathrm{ml})$, were then challenged with HIV-1.

HIV-1 challenge studies. Viral stocks of the HIV-1 strain NL4-3 (2) were used in the challenge experiments. In certain experiments, a primary syncytium-inducing HIV-1 clinical isolate was also utilized. The preparation of viral stocks and their titration (by the use of tissue culture infectious doses) were previously described in detail (23). The G418-selected mixed populations of HIV-1-susceptible cells that expressed the indicated SFvs were maintained in G418-free medium for at least 2 weeks prior to HIV-1 infection. Parental SupT1 cells alone and cells transduced with anti-IN SFvs, CAT, or the anti-HBV core SFv were incubated with infectious cell-free HIV-1 $1_{\mathrm{NL} 4-3}$ virions at various input multiplicities of infection (MOIs) (0.04 to 0.06$)$ for $4 \mathrm{~h}$. The cells were washed four times with prewarmed serum-free medium and then maintained in growth medium. Every 3 days, cells were split 1:2 to maintain a cell density of approximately $10^{6} / \mathrm{ml}$ and the culture supernatants were collected for HIV-1 p24 antigen analyses. The HIV-1 p24 antigen levels in supernatants were determined by ELISA (Dupont). Cell viability was monitored by trypan blue exclusion staining.

One-step viral growth and 2-LTR DNA assays. One-step HIV-1 infectivity experiments were performed with nontransduced SupT1 cells and SupT1 cells which were transduced with different anti-IN SFvs. HIV-1 ${ }_{\mathrm{NL4}-3}$ at a high MOI (2.0) was used to infect these cells for $4 \mathrm{~h}$. Cells were then washed with prewarmed serum-free medium and cultured for different time periods. At 4, 6, 8, and $16 \mathrm{~h}$ after HIV-1 infection, cells were harvested by low-speed centrifugation and washed with PBS. Total cellular DNA was prepared by a quick lysis method, as previously described $(1,68)$. This included suspension of $10^{6}$ cells in $100 \mu$ l of solution A (10 mM Tris- $\mathrm{HCl}[\mathrm{pH} 8.3]$ and $100 \mathrm{mM} \mathrm{KCl})$ and lysis in $100 \mu \mathrm{l}$ of solution B (10 mM Tris- $\mathrm{HCl}[\mathrm{pH} 8.3], 1 \%$ Tween 20 , and $1 \%$ Nonidet P-40) containing $25 \mu \mathrm{g}$ of proteinase $\mathrm{K}$, followed by incubation at $60^{\circ} \mathrm{C}$ for $60 \mathrm{~min}$. The samples were then boiled for $30 \mathrm{~min}$ to inactivate the proteinase K. HIV-1 infection was confirmed by assaying for the synthesis of viral DNA by PCR with the SK38-SK39 primer pair, which is located in the gag region of the HIV-1 genome, using $5 \mu \mathrm{l}$ of cell lysate $(1,42)$. To amplify viral 2-LTR DNA moieties, a nested PCR was developed with two primer pairs: M667-U32 and U5-2LTRU3-2LTR. (M667 is 5'-GGCTAACTAGGGAACCCACTG-3', U32 is 5'-GGC AAAAAGCAGCTGCTT-3', U5-2LTR is 5'-GAGATCCCTCAGACCCTTTT AG- $3^{\prime}$, and U3-2LTR is $5^{\prime}$-GTAAGTGGATATCTGATCCCTG-3' ${ }^{\prime}$.) The first

\section{Structure of HIV-1 Integrase}

\begin{tabular}{|c|c|c|c|c|c|c|}
\hline \multirow{2}{*}{\multicolumn{2}{|c|}{$\begin{array}{l}\text { Zinc-Finger-like } \\
\text { Domain }\end{array}$}} & \multicolumn{4}{|c|}{ Core (Catalytic) Domain } & \multirow{2}{*}{$\begin{array}{l}\text { Nonspecific } \\
\text { DNA binding } \\
\text { domain }\end{array}$} \\
\hline & & 64 & 116 & 141 & 152 & \\
\hline $\mathrm{HH}$ & CC & D & D & & E & \\
\hline
\end{tabular}

Binding domain of anti-IN mAbs

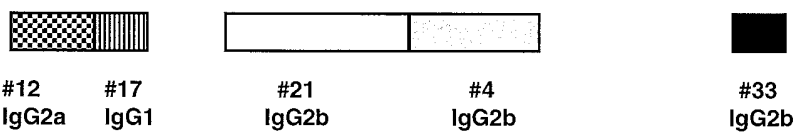

\section{Murine anti-IN IgG binding affinities:}

$\# 12>\# 17 \& \# 33>\# 21 \& \# 4$

FIG. 1. Binding domains of anti-HIV-1 IN monoclonal antibodies. Each of the anti-HIV-1 IN MAbs was purified, and the in vitro binding affinities of the purified antibodies to bacterially expressed HIV-1 IN protein (derived from the BRU strain) were analyzed via ELISA. The binding domain of each was mapped by using various deleted IN proteins (6). Note that the functional motifs in HIV-1 IN are illustrated at the top of the diagram, although precise boundaries are not yet fully defined.

PCR, performed with primer pair M667-U32, was for 29 cycles in a $25-\mu 1$ volume with reaction conditions as follows: $5 \mathrm{~min}$ at $94^{\circ} \mathrm{C}$ (for denaturation), $94^{\circ} \mathrm{C}$ for 1 $\min 20 \mathrm{~s}, 45^{\circ} \mathrm{C}$ for $45 \mathrm{~s}$, and then $72^{\circ} \mathrm{C}$ for $10 \mathrm{~min}$ (for extension). From the first PCR reaction mixture, $5 \mu \mathrm{l}$ of PCR product was further amplified with the U3-2LTR-U5-2LTR primer pair for 25 cycles under the same amplification conditions as were used for the first PCR round. The PCR products were separated on $1.5 \%$ agarose gels, transferred onto membranes, and hybridized with a ${ }^{32} \mathrm{P}-5$ '-end-labeled oligonucleotide (AA50) probe specific for the U5 sequence and a ${ }^{32} \mathrm{P}$-labeled SK19 probe specific for $g a g$ sequences (1). The oligonucleotide probes were ${ }^{32} \mathrm{P}$ labeled by using $\left[\alpha^{-}{ }^{32} \mathrm{P}\right] \mathrm{dATP}(3,000 \mu \mathrm{Ci}$; Dupont NEN) in a T4 kinase reaction (48). The hybridized products were analyzed with a PhosphorImager (Molecular Dynamics). The details of the construction of the 2-LTR DNA plasmid control which was used in this PCR reaction have been previously published (40)

Immunostaining for SFv expression. Subcellular localization of intracellularly expressed SFv proteins within the cells was determined by indirect immunofluorescence assays (19). NIH 3T3 cells were cultured on eight-chambered glass slides overnight. After transfection of different retroviral SFv expression plasmids by a calcium phosphate coprecipitation method (48), cells were then fixed in $3.5 \%$ formaldehyde at room temperature for $10 \mathrm{~min}$ followed by treatment with a $0.1 \%$ Nonidet P-40-PBS solution for $10 \mathrm{~min}$ at room temperature; they were then washed twice with PBS. Cells were incubated with a 1:200 dilution of goat anti-mouse polyclonal IgG Fab fragment (Nordic Immunology, Inc.) and a 1:500 dilution of FluoroLink-Cy2-labeled donkey anti-goat IgG (Amersham Life Science) for $2 \mathrm{~h}$ at $37^{\circ} \mathrm{C}$. After being washed five times in PBS, cells were mounted and analyzed by epifluorescence microscopy.

\section{RESULTS}

Cloning of the anti-IN SFvs in retroviral and bacterial expression vectors. Sequences encoding $V_{L}$ and $V_{H}$ chains of the anti-IN MAb were cloned from five murine hybridoma cell lines. These included hybridomas 4, 12, 17, 21, and 33, which produce MAbs that bind to different domains of HIV-1 IN, as assessed by ELISA and Western blotting (6). The binding regions and relative affinities reported for each of the anti-IN IgGs are summarized in Fig. 1. At least three independent clones, representing the heavy or light chains, were subjected to sequence analysis. The complete predicted amino acid sequences of the complementarity-defining regions (CDRs) of each anti-IN SFv were obtained (Fig. 2). It is of note that the critical CDR3 domains, so important in specific epitope binding (56) in the $\mathrm{V}_{\mathrm{H}}$ chains of the various HIV-1 IN MAbs, differ markedly. After ligation of $\mathrm{V}_{\mathrm{L}}$ and $\mathrm{V}_{\mathrm{H}}$ chains into a single fragment by utilizing the flexible linker (GGGGS) $)_{3}$ (5), each of the SFv fragments was cloned in both a murine leukemia 


\begin{tabular}{|c|c|c|c|}
\hline \multicolumn{4}{|c|}{ LIGHT CHAIN: } \\
\hline & CDR1 & CDR2 & CDR3 \\
\hline sFv\#33: & KASQDIYKYXA & YTSTLQP & LQYDNLW \\
\hline SFv\#12: & RSSQSLVHRNGNTYLH & KVSNPFS & SQSRHVP \\
\hline sFv\#21: & KSSLSLLDSDGKTYLN & LVSKLDS & CQGTHFP \\
\hline sFv\#4: & RSSQSLVHSNRDTYLH & KVSNRFS & SQSTHVPP \\
\hline sFv\#17: & RSSQTXVHSDGNTYLE & KISNRFS & FQGSHVP \\
\hline \multicolumn{4}{|c|}{ HEAVY CHAIN: } \\
\hline sFv\#33: & SYAMS & SISSGGNTYYPDSVKG & LDTTVEGDWYFDV \\
\hline sFv\#12: & TYLIE & VINPGGGGIDYNEKFKG & YTDYAMDY \\
\hline sFv\#21: & DYEMH & AIDPETSGTAYNQNFKG & GFAY \\
\hline sFv\#4: & DYYMS & FIRNKANGYTTEYSVSVKG & EGVGNWFVY \\
\hline sFv\#17: & EYEMH & AVDPETGGTAYNOKFKG & QGLGY \\
\hline
\end{tabular}

FIG. 2. Light- and heavy-chain complementarity-defining region (CDR) sequences of anti-HIV-1 IN SFvs. The CDR amino acid sequences of anti-HIV-1 IN SFvs were determined by using the Kabat antibody sequence database (19, 22)

virus-based retroviral expression vector, pSLXCMV (as shown in Fig. 3A), and a bacterial expression vector, pET19b (Fig. 3B). The anti-IN or control anti-HBV core antigen SFvs were expressed from an internal cytomegalovirus promoter in the pSLXCMV vector. The complete SFv constructs, including linker sequences, comprise 750 to $820 \mathrm{bp}$ and encode proteins of approximately 28.5 to $30 \mathrm{kDa}$.

Construction of SFvs which contain an NLS. Subcellular targeting of proteins plays an important role in their function (31). Although we have previously demonstrated that the HIV1 Rev protein, which naturally shuttles between the nucleus and cytoplasm, can be trapped in the cytoplasmic fraction by complexing with cytoplasm-localized anti-HIV-1 Rev SFv (38), there are no data to predict how anti-HIV-1 SFvs may function when NLSs are added. For construction of anti-HIV-1 IN SFvs which carry an NLS, the HIV-1 Tat NLS was selected (63). The amino acid sequence is as follows: $\mathrm{NH}_{2}$-GRKKRRQRRRAH QN-COOH. As shown in Fig. 3C, the NLS domain was placed downstream of the linker and upstream of the heavy chain of IN SFv33 to generate pT7IN-SFv33/NU.

The subcellular locations of anti-HIV-1 IN SFv33 and SFv33/ NU were determined after transient transfection of these two corresponding retroviral expression vectors into NIH 3T3 cells by a calcium phosphate coprecipitation method in culture chambers. Twenty-four hours after transfection, the cells were fixed and immunostained with purified goat anti-mouse polyclonal IgG Fab fragment. As shown in Fig. 4B and D, the SFv which contained the HIV-1 Tat NLS domain localized within the nucleus, especially surrounding the inner nuclear membrane, while IN SFv33 showed mainly cytoplasmic staining with nuclear exclusion (Fig. 4A and C). As IN SFv3/NU is translated in the cytoplasm, staining is not solely localized to the nuclear compartment.

SFv gene expression in $E$. coli and SFv-HIV-1 IN interactions. To determine if the efficiencies of binding of recombinant SFvs to the HIV-1 IN protein would correlate with those of the parental murine IgGs in vitro, all of the anti-IN SFvs were first cloned in the pET19b vector. All five of the anti-IN SFvs were expressed to detectable levels in bacterial cells (Fig. 5). It is important to note that differences in the intensity of $\mathrm{SFv}$ bands on Western blots may be secondary to epitope differences on the SFvs, to which the detection antibody binds (61).

To quantify binding activity, specific HIV-1 IN SFvs (demonstrated to inhibit HIV-1; see below) were compared with parental murine MAbs in a standard ELISA assay with immobilized HIV-1 IN. Careful in situ renaturation of purified antiHIV-1 IN SFv4 and SFv33 on $\mathrm{Ni}^{2+}$ affinity columns allowed recovery of the major fraction of the preparation as competent refolded protein. As the data in Fig. 6A demonstrate, SFvs

A

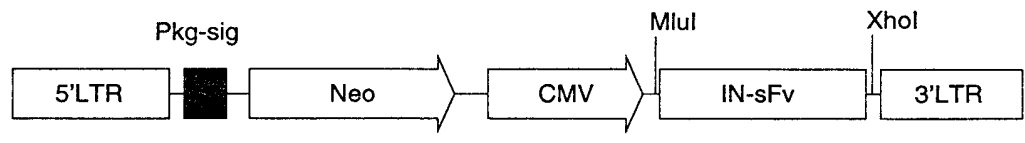

B

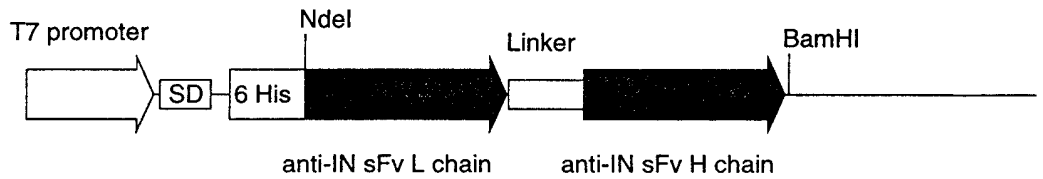

C

anti-IN sFv L chain $\%$ Tat NLS anti-IN sFv H chain

GGGGS Linker
FIG. 3. Schematic representations of anti-HIV-1 IN SFv gene constructs in the retroviral expression vector pSLXCMV (A) and the bacterial T7 RNA polymerase promoter-based vector pET19b (B). (C) Schematic representation of the anti-HIV-1 IN SFv structure, which contains the Tat NLS. Pkg-sig, packaging signal; CMV, cytomegalovirus promoter; Neo, neomycin resistance gene; His, six residues in the polyhistidine tag domain; T7, T7 RNA polymerase promoter; linker, (GGGGS) $)_{3}$ SFv linker domain; SD, splice donor site. 
A)

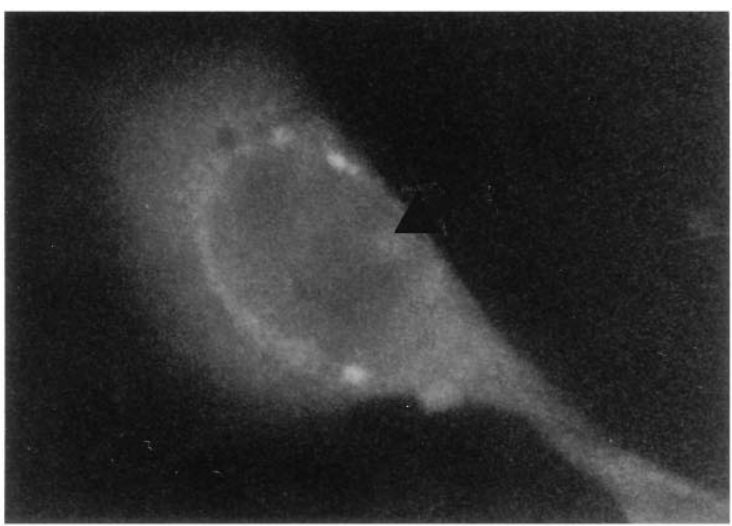

C)

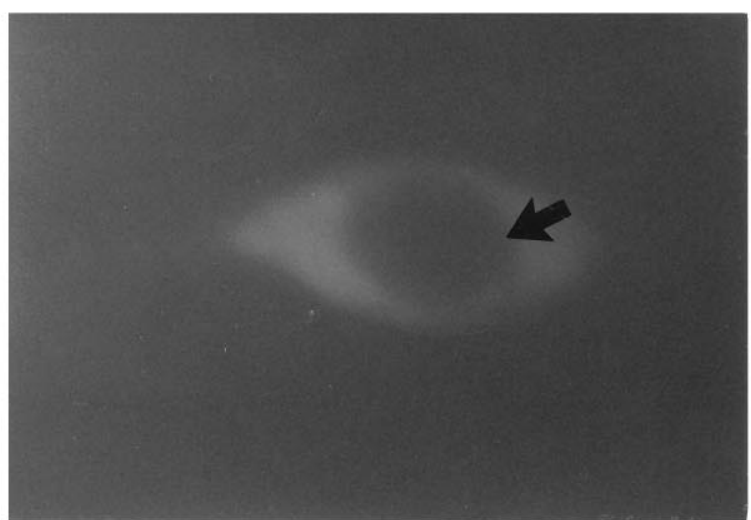

B)

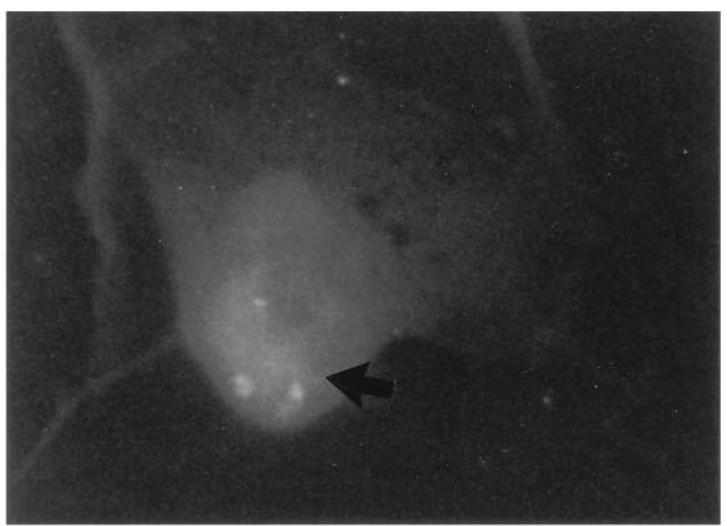

D)

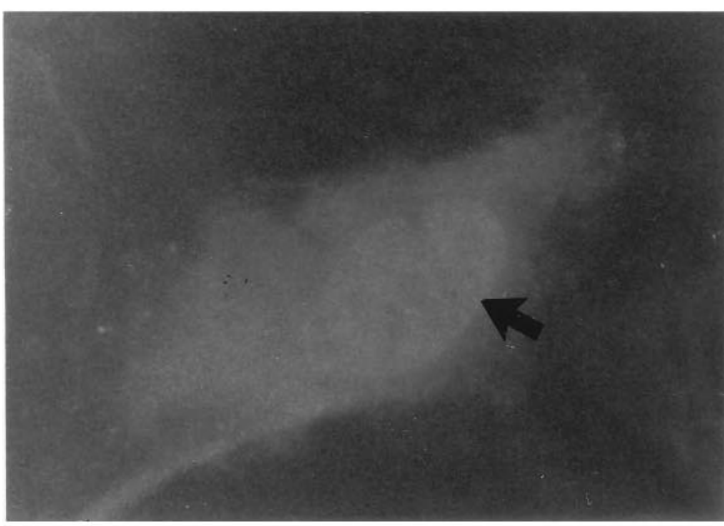

FIG. 4. Analysis of SFv protein expression in transfected NIH 3T3 cells. Immunofluorescent staining of the intracellular anti-IN SFv moieties was demonstrated in situ. Transiently transfected NIH 3 T3 cells were fixed and immunostained with purified goat anti-mouse polyclonal IgG Fab fragment, using a fluorescein isothiocyanate (Cy2)-conjugated donkey anti-goat IgG. (A and C) NIH 3 T3 cells transduced with pSLXCMV-anti-IN SFv33 showed mainly cytoplasmic staining and nucleoplasm exclusion. (B and D) NIH 3 T3 cells transduced with pSLXCMV-anti-IN SFv33/NU (which carries the Tat NLS) showed nuclear and some cytoplasmic staining. Arrows point to the nuclear compartments in the illustrated cells. Cy2-labeled antibodies to the CAT gene (control) gave no specific immunostaining in these cells (data not illustrated). These photomicrographs are representative of three independent experiments. Magnification, $\times 400$.

have similar binding patterns but, as expected, somewhat lower affinities for the HIV-1 IN compared with their parent antibodies. In contrast, near-background levels indicate very low and nonspecific binding to ASV IN by parent MAbs and SFvs (Fig. 6B).

The specificities of anti-IN SFv33 and SFv4 binding were next investigated by immunoblotting. Total protein from $E$. coli cells induced for the production of HIV-1 IN was separated by PAGE and probed with either purified murine anti-IN IgG or recombinant anti-HIV-1 IN SFv33 or SFv4. Three major bands were detected, corresponding to full-length HIV-1 IN (32 kDa) and two shorter IN-related products, which result from internal initiation at methionine residues 22 and 154 downstream from the natural start codon in the expression vector (Fig. 7) (34). All three products were recognized similarly by the SFvs and the parental monoclonal IgG.

Inhibition of HIV-1 replication in human T-lymphoid cells that express anti-IN SFvs. Retroviral vectors are widely used because of their high transduction efficiency (54). pSLXCMVCAT, a previously reported retroviral construct, has been shown to maintain stable levels of expression of the CAT reporter gene in the T-lymphocytic SupT1 and CEM cell lines for at least six months (23). High transduction efficiencies ( $>60 \%$ at MOIs of 5 to 10 ) were reported when the pSLX-
CMV- $\beta$-galactosidase construct was used in transduced SupT1 and CEM cells, with staining for $\beta$-galactosidase expression (23). To analyze the expression of the anti-IN SFv genes in human T-lymphocytic cells, transduced SupT1 cells were G418 selected and mixed cell populations were maintained in G418containing medium for at least 4 weeks. After G418 selection, cells were grown in medium without the antibiotic for 14 days. As expected from previous studies (68), similar expression of the different anti-IN SFvs was observed in mixed SupT1 cell populations by Western blotting with goat anti-mouse IgG (data not illustrated). As previously reported (23), those cells transduced with the pSLXCMV retroviral vector were found to maintain SFv protein expression for 3 to 4 months of passage in culture. It is of note that cell growth curves and viability were not altered by transduction of either anti-IN SFv, CAT, or retroviral backbone control vectors (data not illustrated).

To determine if the intracellular expression of anti-IN SFvs was able to prevent HIV-1 replication in susceptible T-lymphoid cells, HIV-1 challenge experiments, utilizing the highly cytopathic viral strain NL4-3, were conducted with SupT1 cells stably transduced with IN SFvs (SupT1 IN SFv cells) (2). The infectivity assays were performed with transduced mixed SupT1 cell populations. For HIV-1 challenge experiments, IN SFv-transduced SupT1 cells, CAT-, anti-Rev SFv-, and anti- 
A

B

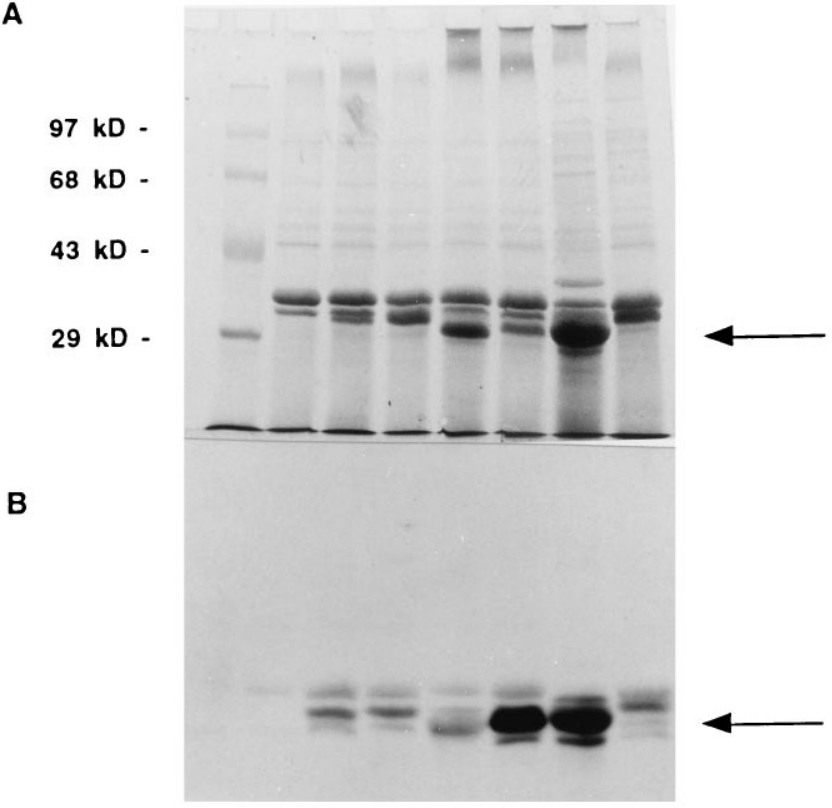

FIG. 5. Assays of anti-HIV-1 IN SFv gene expression in E. coli. After $4 \mathrm{~h}$, IPTG-induced bacterial cultures were lysed and the insoluble fraction was subjected to sodium dodecyl sulfate (SDS)-12\% PAGE. After transfer to membranes, the samples were immunoblotted with goat anti-mouse IgG antibody. (A) Coomassie blue staining of SDS-PAGE gels. (B) Immunoblotting of SFvs expressed in bacterial cultures. $\mathrm{M}$, molecular mass marker lane; $\mathrm{C}$, negative-control lane (nontransformed bacteria). The arrows indicate specific SFv bands. Note that IN SFv33/NU migrates more slowly than other SFvs because of its slightly higher molecular weight.

HBV core protein SFv-transduced SupT1 cells, and nontransduced SupT1 cells were infected with HIV- $1_{\mathrm{NL4}-3}$ (MOI, 0.04 or 0.06 ). The spread of HIV-1 in the cultures was determined by quantitating the levels of HIV-1 p24 antigen released into the culture medium (Fig. 8). Low levels of HIV-1 p24 antigen were observed in the supernatants of SupT1 IN SFv33 and SFv4 as well as control cells infected with HIV- $1_{\mathrm{NL} 4-3}$ at early time points after infection. Parental nontransduced, CATtransduced, and anti-HBV core SFv-transduced cells supported vigorous replication of HIV-1, as shown by the initial increases in HIV-1 p24 antigen, which peaked at approximately 15 to 22 days with MOIs of 0.04 to 0.06 (Fig. 8A and B). HIV-1 p24 antigen levels subsequently decreased in the control cells because of the cytopathic effects of viral replication in these cells and subsequent cell death (data not illustrated). On days 15 to 22 postinfection, both SupT1 IN SFv33 and SFv4 mixed cell populations showed approximately 95 to $98 \%$ inhibition of HIV-1 p24 antigen production compared with the nontransduced SupT1 cells and cells expressing CAT, anti-HBV core SFv (controls), or anti-IN SFv17 and SFv21. Anti-IN SFv12 demonstrated somewhat more modest inhibitory effects on HIV-1 expression in multiple experiments. It is of interest that SFv33 binds to the carboxyl terminus and SFv4 binds to the central catalytic domain of HIV-1 IN (Fig. 1). As seen in Fig. 8B, when anti-IN SFv33 and SFv4 were compared with antiRev D8 SFv, significantly lower levels of HIV-1 expression were observed in the cells expressing IN SFv33 while comparable inhibition was demonstrated with IN SFv4. These results indicate that HIV-1 replication was dramatically reduced or inhibited in the SupT1 IN SFv33 and SFv4 cells. In addition, anti-IN SFv17 and SFv21 and the control anti-HBV core SFv
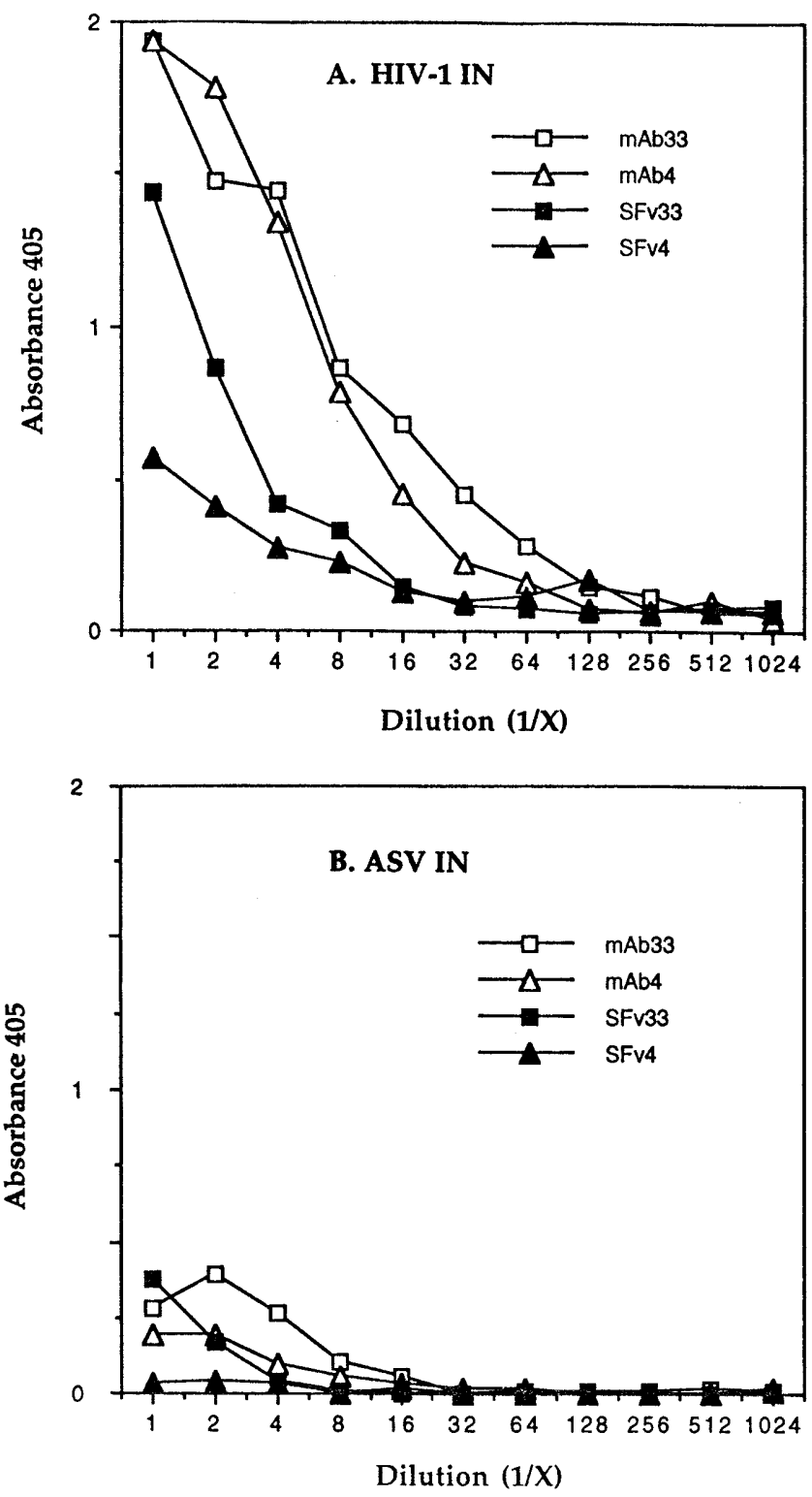

FIG. 6. In vitro binding activities of anti-IN SFv33 and SFv4. (A) The in vitro binding affinities of SFvs for recombinant HIV-1 IN protein were measured in a standard ELISA assay (6). (B) As a control, ELISA plates were coated with the same concentration of maltose-binding protein-ASV virus (ASV) IN. E. coliexpressed anti-IN SFv33 and SFv4 were purified on $\mathrm{Ni}^{2+}$ columns under ureadenaturing conditions. After renaturing in PBS, HIV-1 IN-specific binding affinities were determined by using parent anti-HIV-1 IN murine IgG or purified SFv proteins, starting at $4 \mu \mathrm{g} / \mathrm{ml}$ and then serially diluted.

did not significantly inhibit HIV-1 replication in multiply repeated experiments, demonstrating the intracellular specificity of anti-IN SFvs. Interestingly, SFv12's relatively lower efficiency of neutralizing HIV-1 infection, compared with those of IN SFv33 and SFv4, may correlate with the reduction in binding affinity of its parental MAb for IN derived from the HIV$1_{\mathrm{NL4-3}}$ strain (7a).

HIV-1 replication can be inhibited by both cytoplasm- and nucleus-localized IN SFvs. Upon infection with the highly cytopathic HIV-1 strain NL4-3, IN SFv33- and SFv4-transduced SupT1 cells showed delayed and weak cytopathic effects, as observed by syncytium formation and cell death (data not 


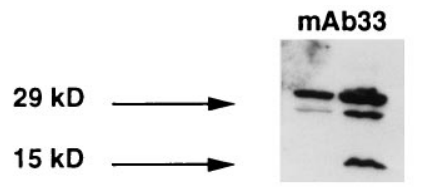

12

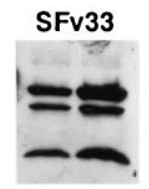

34

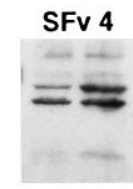

56
FIG. 7. Binding of anti-HIV IN SFv to IN as measured by immunoblotting. E. coli cultures which expressed HIV-1 IN proteins were lysed, and total protein was separated by 10 to $20 \%$ gradient SDS-PAGE. After transfer of proteins to membranes, blots were probed with either purified murine anti-IN IgG antibodies (lanes 1 and 2) or E. coli-expressed SFv proteins (lanes 3 to 6), using the ECL system (Amersham). Paired lanes represent 1- and 3-h induction periods for IN synthesis. Three major bands were detected, which correspond to full-length HIV-1 IN (32 kDa) and two shorter IN-related products, from internal initiations at methionine residues 22 and 154 from the natural start codon in the expression vector (34).

illustrated). This suggests that expression of anti-IN SFv within the cytoplasmic compartment protected cells against the cytopathic effects of HIV-1. In the HIV-1 life cycle, reverse-transcribed double-stranded linear DNA has to gain access to nuclear chromatin prior to integration into the host genome. IN may play a role in shuttling the HIV-1 preintegration complex into the nuclear compartment (32). In order to determine if anti-IN SFvs could interrupt IN function when the SFv was largely sequestered in the cell nucleus, we used the construct that included an NLS to guide IN SFv33 into the nucleus. The HIV-1 Tat NLS was used, as it at least represents a natural retroviral NLS (61). Cytoplasmic and nuclear SFvs showed similar levels of expression in the SupT1 cells as determined by immunoblotting (data not illustrated). SupT1 IN SFv33 and SFv33/NU cells were infected with HIV-1 $1_{\text {NL4-3 }}$ as summarized in Fig. 8C. Both showed resistance to HIV-1 infection, although the cytoplasmic SFv seemed to produce a somewhat more efficient blockade of HIV-1 infection. Further studies are under way to determine the molecular mechanisms that account for such differences. Importantly, as the IN-SFv33/NU is translated in the cytoplasm and immunofluorescence analysis shows both nuclear and cytoplasm staining, it is possible that this moiety's effects on HIV-1 replication may be based on the presence of SFv molecules in either subcellular compartment.

Intracellular mechanisms of the effects of anti-IN SFv on inhibition of HIV-1 expression. To determine if the observed decreases in HIV-1 p24 antigen levels correlated with a specific intracellular inhibition of HIV-1 integrase activity or were merely secondary to other effects of intracellular expression of anti-IN SFv33 in T-lymphoid cells, experiments were performed at a high MOI of 2.0 to obtain one-step growth curves of HIV-1 $1_{\text {NL4-3 }}$ replication (see Materials and Methods). Sitespecific mutagenesis experiments have shown that inactivation of HIV-1 IN blocks the integration of linear double-stranded viral DNA into chromosomal DNA. Consequently, HIV-1 DNA is joined at its ends by cellular ligases to form 2-LTR circles $(26,41)$. To monitor HIV-1 IN inhibition in the infected cells, levels of HIV-1 2-LTR DNA were compared by semiquantitative PCR. This approach is considered semiquantitative since it utilizes two rounds of amplification with nested primers. The primer pair M667-U32, nested with primer pair U3-2LTR-U5-2LTR and probed with AA56, was used in these 2-LTR DNA detection experiments (Fig. 9). For normalization, the amounts of gag sequences within the cells provide a measure of total viral DNA synthesis. Detection of similar amounts of gag DNA indicates that the anti-HIV-1 SFv-transduced or nontransduced cells were infected equally with HIV-1 (61) (Fig. 9). It is of note that analysis of negative-strand, strong-stop HIV-1 reverse transcripts was not included in these analyses, as they are abundant intravirion HIV-1 reverse transcripts (70). Increases in the amounts of HIV-1 2-LTR DNA were detectable in IN SFv33/NU-transduced cells initially at $6 \mathrm{~h}$ after HIV-1 infection, while 2-LTR DNA accumulated to the highest level in IN SFv33-transduced cells at $8 \mathrm{~h}$ postinfection. The levels of 2-LTR DNA in IN SFv33/NU-transduced cells were relatively low, although this moiety was detectable quite early after infection. In contrast, SupT1 control cells first demonstrated 2-LTR viral DNA at $16 \mathrm{~h}$ postinfection. The results, presented in Fig. 9, demonstrate that the detectable levels of HIV-1 2-LTR viral DNA molecules occurred significantly earlier in cells expressing anti-IN SFv33 or SFv33/NU than in the control cells. It is of note that the quite short initial half-life of HIV-1 2-LTR DNA in the first round of infection (see Fig. 9A, lanes 2, at 8 and $16 \mathrm{~h}$ ) has been described previously (55a). Determination of whether anti-IN SFvs also alter HIV-1 2-LTR DNA stability will require further studies. An NL4-3 mutant viral strain, derived from pNL43D116N, in which HIV-1 IN has been inactivated by substitution of Asn for Asp-116 shows increased early levels of this 2-LTR product, which demonstrates the sensitivity of the 2-LTR junction assay (26) (data not illustrated). In sum, the present data suggest that the anti-HIV IN SFv33 and SFv33/NU block the intracellular integration process specifically.

Inhibition of HIV-1 replication by anti-HIV-1 IN SFvs in human PBMC. To evaluate the potential of anti-HIV-1 IN SFvs for clinical application, stimulated human PBMC were transduced with the retroviral vectors that express anti-IN SFv33 or SFv33/NU. The transduction protocol consisted of daily infection of cells with fresh packaging line supernatants for 3 days, leading to transduction efficiencies, as measured by indirect immunofluorescence assay, ranging from 25 to $35 \%$ for different experiments. Considering the mixed cellular complexity of human PBMC, these $35 \%$ transduced, highly expressive cells may represent the dividing fraction which will also be the target cells for high-level HIV-1 expression (23). It is of note that PBMC consisted of similar lymphocytic subpopulations before and after transduction (data not illustrated).

PBMC were challenged with HIV- $1_{\text {NL4-3 }}$ or a syncytiuminducing clinical isolate of HIV-1 (926262-SI). Figure 10 shows a dramatic inhibition of HIV-1 production by anti-IN SFv33 and SFv33/NU. Utilizing anti-HIV-1 Rev (D8) SFv as a positive control, under the same challenge conditions there was a similar dramatic inhibition of HIV-1 p24 antigen production in anti-IN SFv33-transduced human PBMC for 30 days postinfection (Fig. 10).

\section{DISCUSSION}

In this report, we demonstrate that intracellular expression of anti-HIV-1 IN SFvs which specifically target either the HIV-1 IN catalytic or carboxy-terminal domain and are localized to either the nuclear or cytoplasmic compartment markedly decreases HIV-1 replication in both T-lymphocytic cell lines and human PBMC. The significance of this finding is that it provides an opportunity to inhibit HIV-1 replication before integration of viral DNA into the host genome occurs.

Shortly after initiation of infection by a retrovirus, the viral RNA genome is reverse transcribed into a double-stranded DNA form, and this viral DNA molecule is then integrated covalently into the host cell genome via viral IN (37). HIV-1 IN is a multifunctional catalytic enzyme which requires multimerization for activity and may also promote nuclear importation of the preintegration complex of which it is a component (32, $37,41)$. Therefore, it is an excellent target for antiviral therapy 

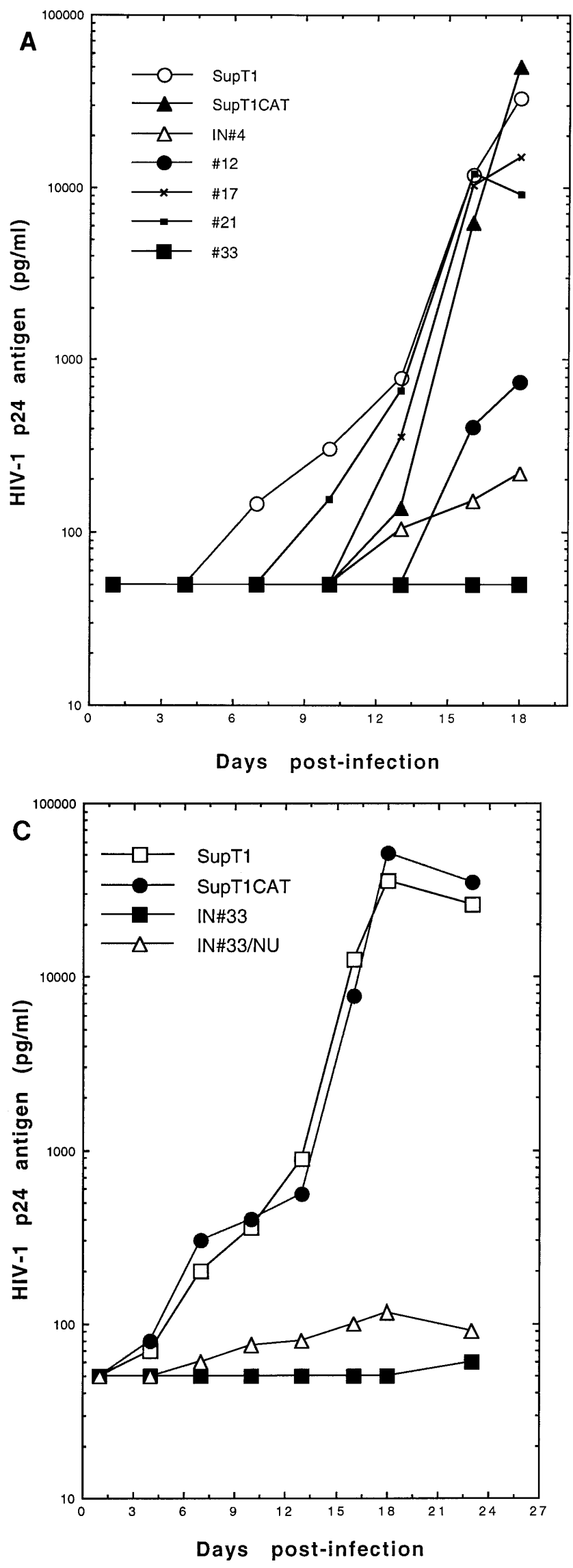

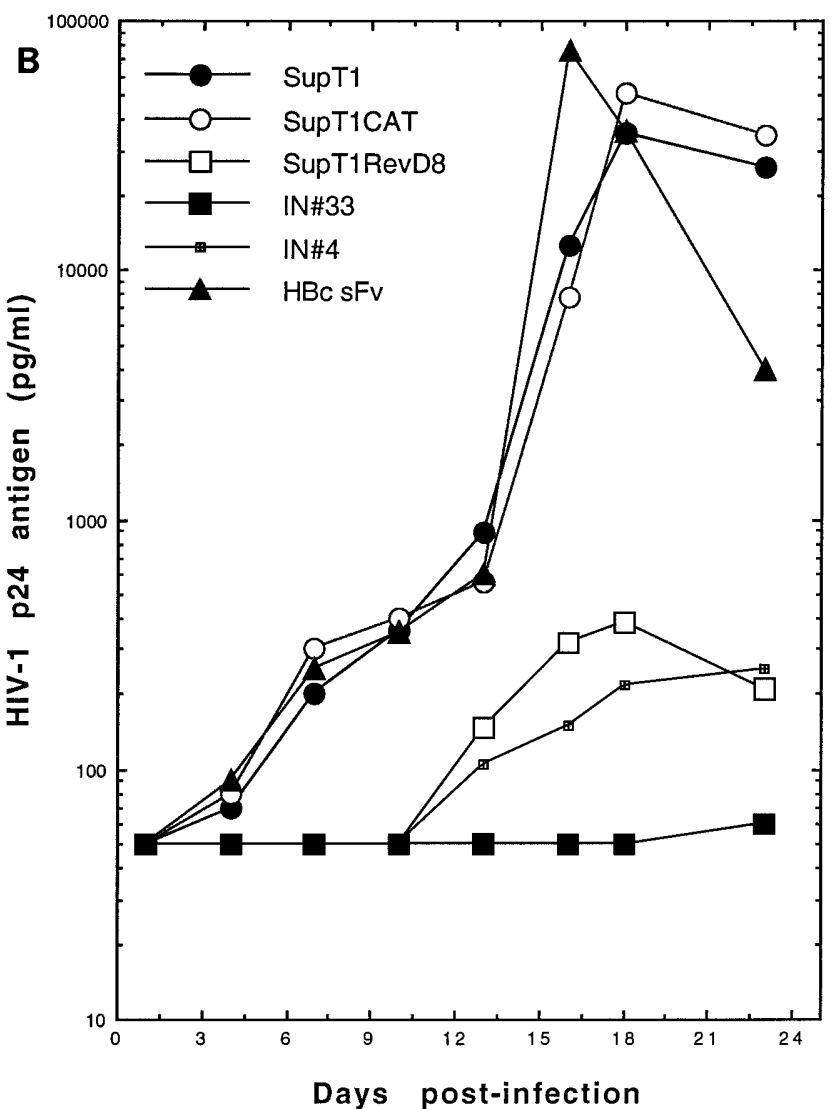

FIG. 8. Inhibition of HIV-1 replication in anti-IN SFv-transduced T-lymphoid cells. SupT1 cells were transduced with CAT, anti-Rev SFv, anti-HBV core antigen (HBc) SFv, and anti-IN SFv retroviral expression vectors (mixed cellular populations). SupT1 cells were infected with HIV-1 $1_{\text {NL4-3 }}$ (MOIs, 0.04 and 0.06 ). (A) Five anti-HIV-1 IN SFv-transduced SupT1 cell lines infected with HIV-1 $1_{\mathrm{NL} 4-3}$ (MOI, 0.04). (B) Comparison of anti-HIV-1 Rev D8 SFv with anti-IN SFv33 and SFv4 (MOI, 0.06). (C) Comparison of anti-IN SFv33 with or without an NLS (MOI, 0.04). HIV-1 replication was quantitated by assaying HIV-1 p24 antigen levels in the culture supernatants by ELISA (Dupont). The data are representative of at least three sets of independent experiments.

by the use of SFv-based strategies (21). Although several in vitro assays can be used to analyze IN enzymatic function, there are still no approved antiviral treatments for HIV-1 infection in which HIV-1 IN has been targeted. Viral protease and RT inhibitors are now both available, and a combination of these agents shows quite promising effects for repression of HIV-1 replication in vivo (58). The combination of multiple anti-HIV-1 inhibitors, directed to several viral protein targets, now becomes a more attractive approach to combat AIDS. Understanding the intracellular function of IN and determining which IN domains can be effectively targeted to inhibit HIV-1 IN function are important for the development of rational strategies. Intracellular localization of functional antiHIV-1 IN SFvs may provide critical information concerning HIV-1 IN function and should aid in the development of gene therapies which target functional motifs of this viral protein.

As multiple HIV-1 proteins have been targeted via specific $\mathrm{SFv}$ strategies, there is now some indication that successful inhibition of HIV-1 replication depends upon neutralizing relevant functional domains within the target protein $(53,61,68)$. The development of a panel of anti-HIV-1 IN murine hybridomas synthesizing IgGs which target different IN domains provided an opportunity not only to produce SFvs for the 

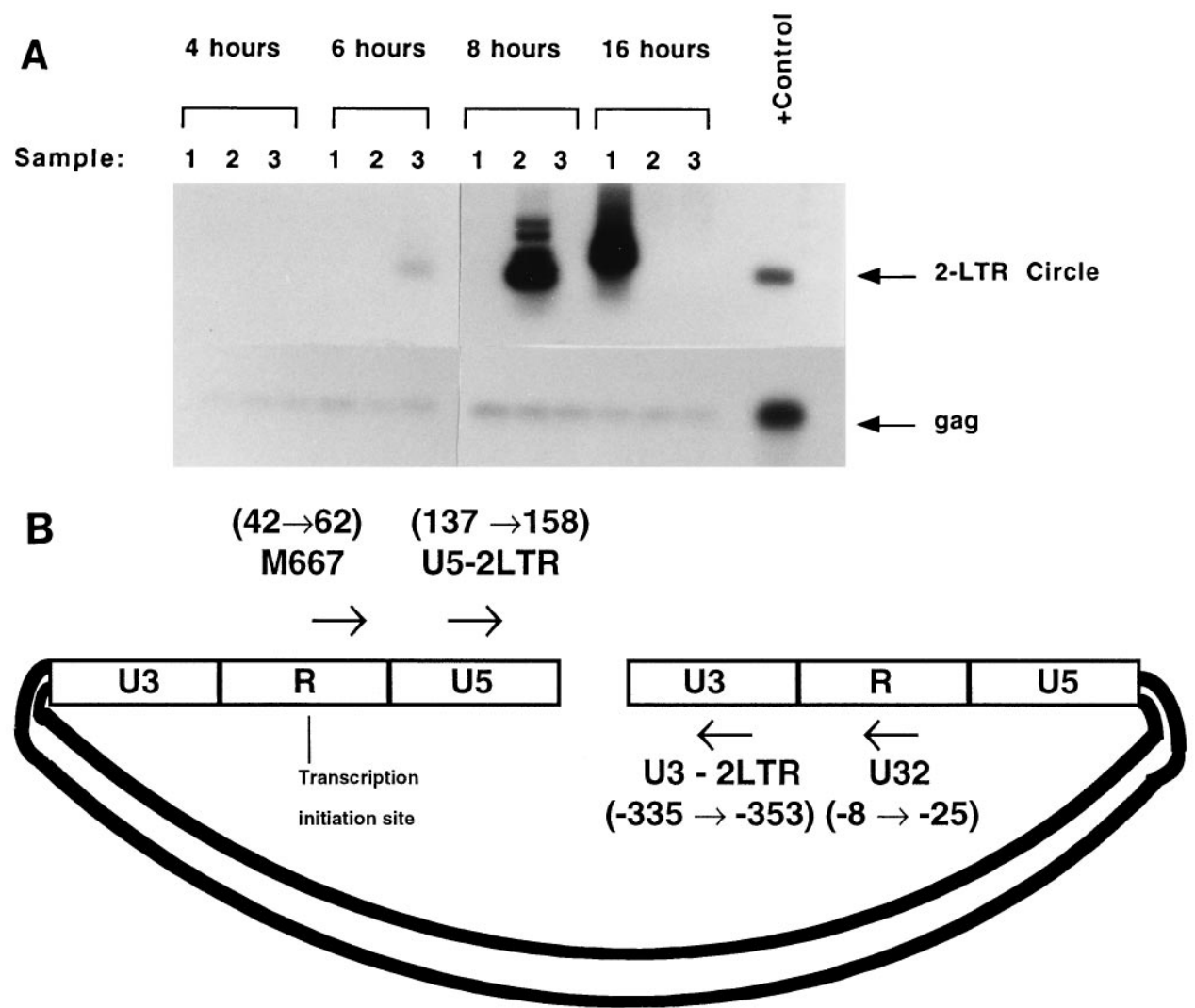

FIG. 9. (A) Semiquantitative PCR analyses of HIV-1 2-LTR DNA in cells expressing anti-IN SFvs. Lanes: 1, SupT1 control; 2, SupT1 SFv33; 3, SupT1 SFv33/NU.

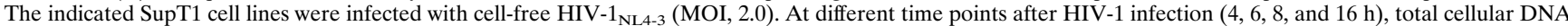
was prepared from cells by a quick lysis procedure $(42,70)$. The DNA $\left(10^{4}\right.$ cell equivalents per lane) was amplified by PCR with the following primer pairs: SK38-SK39, complementary to the gag region of the HIV-1 genome, and nested primers complementary to the HIV-1 DNA junction region (M667-U32 and U5-2-LTR-U3-2-LTR), used to amplify HIV-1 2-LTR DNA (lower and upper panels, respectively). As a positive control, cloned circular HIV-1 2-LTR plasmid DNA was utilized (40). These data are representative of at least two independent experiments. (B) Schematic representation of HIV-1 2-LTR DNA and primer locations.

purpose of anti-HIV-1 gene therapy but also to perform detailed analyses of this critical retroviral protein.

This report describes the incorporation of recombinant antiHIV-1 IN SFv sequences in a retroviral vector. We also demonstrate their potency as gene therapeutic agents which restrict HIV-1 replication in human cells. Intracellular expression of anti-IN SFv renders HIV-1-susceptible cells resistant to highly cytopathic strains of HIV-1. These experiments extend our previous studies with an anti-HIV-1 RT SFv (61). HIV-1 propagation in protected cells was blocked at early stages of viral replication, after the entry of virions into the cellular cytoplasm, rather than at later stages of the HIV-1 life cycle, during which the assembly and production of virions occur $(21,58)$. We observed significant early increases in 2-LTR-containing viral DNA within 4 to $8 \mathrm{~h}$ of infection in cells expressing anti-IN SFv33, amounts similar to that observed in viruses with mutant IN (26). Interestingly, the 2-LTR DNA appeared consistently at least 2 hours earlier in anti-IN SFv33/NU-transduced cells, in which the SFv is located in the nucleus, than in anti-IN SFv33-transduced cells, in which the SFv is located in the cytoplasmic compartment. The time difference suggests that HIV-1 IN may be initially sequestered by the cytoplasmic SFv, delaying nuclear importation of the preintegration complex, where viral DNA ends are joined via nuclear ligase activity. Alternatively, SFv33/NU may facilitate its transport into the nuclear compartment by virtue of binding to the preintegration complex. It is of note that this nested semiquantitative
PCR might detect other unusual viral DNA species, such as head-to-tail linear multimers (55).

As indicated in Fig. 1 and 8A, the effects of anti-HIV-1 do not correspond to the binding affinities of anti-HIV-1 IN antibodies (6). Previously, when a high-binding-affinity anti-Rev SFv (D10) which targets the carboxy terminus of Rev was analyzed, its anti-HIV-1 efficiency was actually lower than that of the SFv Rev D8, which has lower binding affinity but binds to the Rev activation domain (68). Although the anti-HIV-1 IN IgGs which were used in these studies are not finely mapped to precise peptide domains, the general binding pattern of SFvs to IN may provide some clues as to how anti-HIV-1 IN SFv moieties might function. Binding of SFvs to regions in the highly conserved central catalytic domain (IN SFv4) and to the carboxy-terminal domain may indicate that the relevant portions of those domains may be exposed on the surface of the preintegration complex. Data from crystal structure analysis of the core domains of the HIV-1 IN (24) and ASV IN (9) proteins indicate that the conserved region, to which IN SFv4 binds, is flexible in solution. The binding of an SFv to this domain may interfere with the flexibility required for this domain's enzymatic activity. The carboxy terminus of IN, to which SFv33 binds, is the region with the lowest degree of sequence homology among different retroviruses (11). In HIV-1, it has been shown to account for the nonspecific DNA affinity of the protein, which may be involved in target DNA interactions $(27,46)$. When a specific residue in the carboxy 

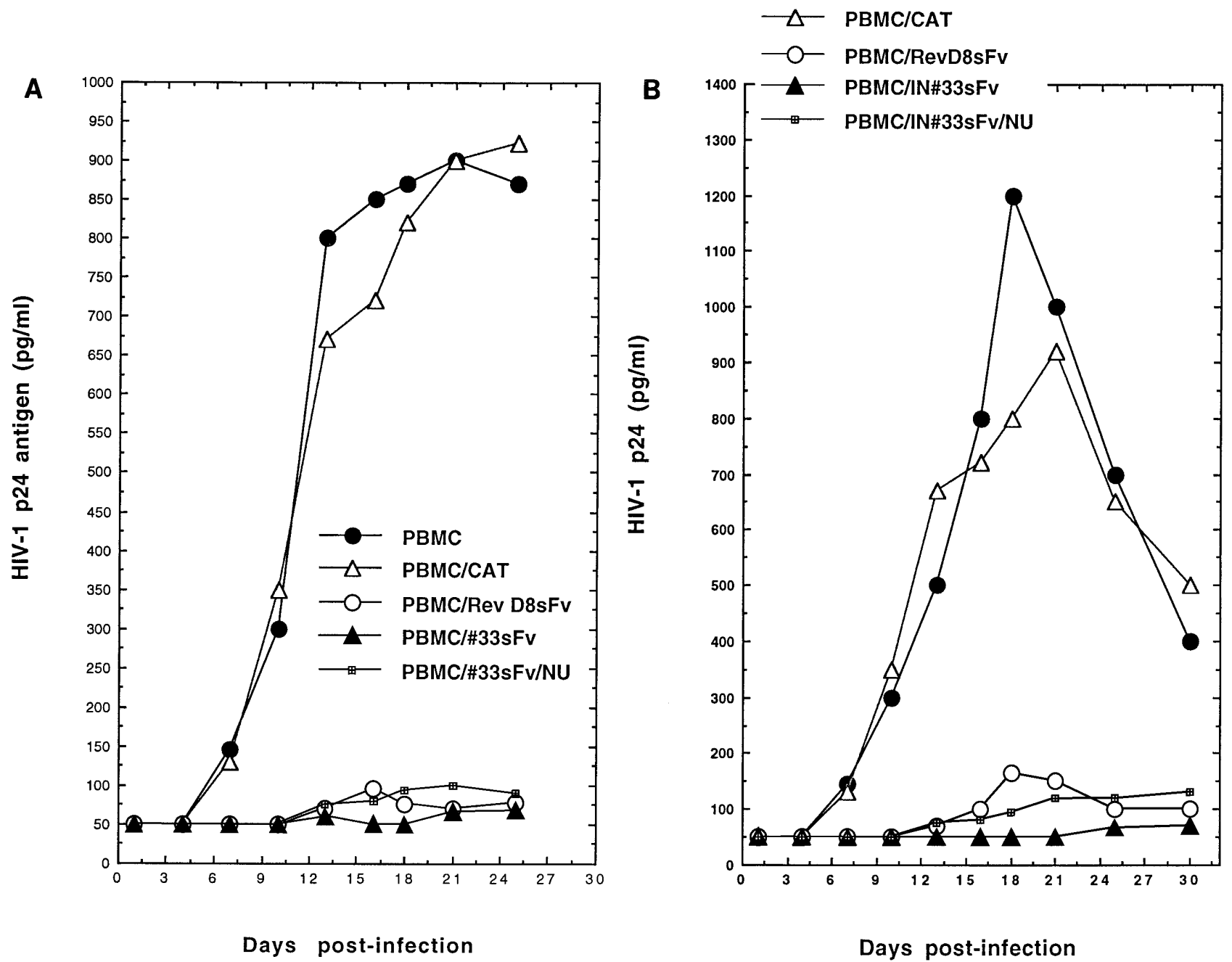

FIG. 10. Anti-IN SFv inhibition of HIV-1 infection in human PBMC. Ficoll-purified human buffy coat PBMC were transduced with CAT-, anti-Rev D8 SFv-, and

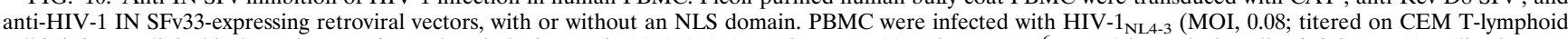
cells) (A) or a clinical isolate of HIV-1 (syncytium-inducing strain 926262; $200 \mathrm{pg}$ of HIV-1 p24 antigen per $10^{6}$ PBMC in 1 ml of medium) (B). HIV-1 replication was quantitated by assaying HIV-1 p24 antigen levels in the culture supernatants by ELISA (Dupont). The data are representative of at least two sets of independent experiments using PBMC from different HIV-1-seronegative donors.

terminus of IN, Trp-235, was replaced by Ala, the ability of the HIV-1 provirus to replicate was abolished (11). It has been speculated, therefore, that this region may be required for correct positioning of processed retroviral LTRs for interaction with the target host cell DNA, either by virtue of an inherent affinity for DNA or through interactions with cellular proteins that may associate with chromatin (11).

IN mutations, which eliminate in vitro enzymatic activity, frequently inhibit viral replication and block the cytopathic effects of HIV-1 in cell culture $(37,41)$. Some mutations in HIV-1 IN have also been shown to alter reverse transcription (51), but no inhibition of reverse transcription was observed with the anti-IN SFvs (Fig. 9A, gag DNA). Blockade of the integration process in anti-IN SFv-expressing cells suggests that the HIV-1 IN enzyme is functionally neutralized in the preintegration complex upon binding of certain SFvs prior to completion of the integration process. Hence, this binding must interrupt some steps before DNA integration into the host genome and establishment of a provirus. This contrasts with the effects of targeting late-phase viral regulatory proteins, such as Rev, with SFvs which would not prevent viral integration into the host genome, as anti-Rev SFvs interfere with the viral life cycle at later stages, after the establishment of a provirus $(19,58)$.

The results of these experiments extend previous findings that single-chain antibodies can be stably expressed, function not only in the cytoplasm but also in the cell nucleus, and are nontoxic to human cells $(14,15,19,20,22,23,49,61,68)$. Furthermore, folding of the SFvs within the cell to form functional binding sites can occur in the reducing environment of the cytoplasm $(7,19)$. By choosing carefully from a relevant panel of anti-HIV-1 IN murine hybridomas, we have shown that the SFvs derived from these hybridomas can be precisely manipulated for appropriate binding to specific epitopes on the target molecules, intracellularly. Thus, these murine SFvs provide the means to control intracellular infections and other diseases, to understand the cellular biological mechanisms leading to a disease state, and, in particular, to aid in choosing the most effective human anti-IN SFvs to develop $(19,56)$. The multiple targets for anti-HIV-1 SFvs will allow the combination of different SFvs for longer-term treatment and more effective protection against HIV-1 replication. The develop- 
ment of resistance mutations in viral proteins, especially HIV-1 $\mathrm{RT}$, may require combinations of various SFvs. The SFvs also serve as valuable reagents with which to explore further the molecular mechanisms of IN and its critical role in the life cycle of HIV-1.

\section{ACKNOWLEDGMENTS}

P.L.-M. and L.D. contributed equally to this work.

We thank Douglas Richman for providing the clinical viral isolates, Didier Trono for helpful discussions, and Rita M. Victor and Brenda O. Gordon for excellent secretarial assistance.

This work was supported in part by USPHS grants CA47486 and CA06927, a grant for infectious disease research from Bristol-Myers Squibb Foundation, and an appropriation from the Commonwealth of Pennsylvania to D.B.-B. and A.M.S., and USPHS grants AI36552, AI38666, AI33810, NS30916, and NS27405, a grant from the Pediatric AIDS Foundation (50605-20-PG), and a grant from Intracel, Inc. to R.J.P.

\section{REFERENCES}

1. Abbott, M. A., B. J. Poiesz, B. C. Byrne, S. Kwok, J. J. Sninsky, and G. D. Ehrlich. 1988. Enzymatic gene amplification: qualitative and quantitative methods for detecting proviral DNA amplified in vitro. J. Infect. Dis. 158: $1158-1168$.

2. Adachi, A., H. E. Gendelman, S. Koenig, T. Folks, R. Willey, A. Rabson, and M. A. Martin. 1986. Production of acquired immunodeficiency syndromeassociated retrovirus in human and nonhuman cells transfected with an infectious molecular clone. J. Virol. 59:284-291.

3. Andrake, M. D., and A. M. Skalka. 1995. Multimerization determinants reside in both the catalytic core and C-terminus of avian sarcoma virus integrase. J. Biol. Chem. 270:29299-29306.

4. Ausubel, F. M., R. Brent, R. E. Kingston, D. D. Moore, J. G. Siedman, J. A. Smith, and K. S. Struhl (ed.). 1994. Current protocols in molecular biology, vol. 1. John Wiley \& Sons, Inc., New York.

5. Batra, J. K., D. FitzGerald, M. Gately, V. K. Chaudhary, and I. Pastan. 1990. Anti-Tac (Fv)-PE40, a single chain antibody Pseudomonas fusion protein directed at interleukin 2 receptor bearing cells. J. Biol. Chem. 265:1519815202 .

6. Bender, D. B., J. Kulkosky, and A. M. Skalka. 1994. Monoclonal antibodies against HIV type 1 integrase: clues to molecular structure. AIDS Res. Hum. Retroviruses 10:1105-1115.

7. Biocca, S., F. Ruberti, M. Tafani, P. Pierandrei-Amladi, and A. Cattaneo. 1995. Redox state of single chain Fv fragments targeted to the endoplasmic reticulum, cytosol and mitochondria. BioTechniques 13:1110-1115.

7a.Bizub-Bender, D., and A. Skalka. Unpublished observations.

8. Brown, P. O., B. Bowerman, H. E. Varmus, and J. M. Bishop. 1987. Correct integration of retroviral DNA in vitro. Cell 49:347-356.

9. Bujaca, G., M. Jaskolski, J. Alexandratos, A. Wlodawer, G. Merkel, R. A. Katz, and A. M. Skalka. 1995. High resolution structure of the catalytic domain of avian sarcoma virus integrase. J. Mol. Biol. 253:333-346.

10. Bukrinsky, M., N. Sharova, and M. Stevenson. 1993. Human immunodeficiency virus type 12 -LTR circles reside in a nucleoprotein complex which is different from the preintegration complex. J. Virol. 67:6863-6865.

11. Cannon, P. M., E. D. Byles, S. M. Kingsman, and A. J. Kingsman. 1996. Conserved sequences in the carboxyl terminus of integrase that are essential for human immunodeficiency virus type 1 replication. J. Virol. 70:651-657.

12. Carteau, S., J. F. Mouscadet, H. Goulaouic, F. Subra, and C. Auclair. 1993. Effect of topoisomerase inhibitor on the vitro HIV DNA integration reaction. Biochem. Biophys. Res. Commun. 192:1409-1414.

13. Carteau, S., J. F. Mouscadet, H. Goulaouic, F. Subra, and C. Auclair. 1993. Inhibitory effect of the polyanionic drug suramin on the in vitro HIV DNA integration reaction. Arch. Biochem. Biophys. 305:606-610.

14. Chen, I. S.-Y., J. Bagley, and W. A. Marasco. 1994. Intracellular antibodies as a new class of therapeutic molecules for gene therapy. Hum. Gene Ther. 5:595-601.

15. Chen, I. S.-Y., Y. Khouri, J. Bagley, and W. A. Marasco. 1994. Combined intra- and extracellular immunization against human immunodeficiency virus type 1 infection with a human anti-gp120 antibody. Proc. Natl. Acad. Sci. USA 91:5932-5936.

16. Craigie, R., T. Fujiwara, and F. Bushman. 1990. The IN protein of Moloney murine leukemia virus processes the viral DNA ends and accomplishes their integration in vitro. Cell 62:829-837.

17. Cullen, B. R. 1991. Human immunodeficiency virus as a prototypic complex retrovirus. J. Virol. 65:1053-1056.

18. Dropulic, B., and K.-T. Jeang. 1994. Gene therapy for human immunodeficiency virus infection: genetic antiviral strategies and targets for intervention. Hum. Gene Ther. 5:927-939.

19. Duan, L.-X., O. Bagasra, M. A. Laughlin, J. W. Oakes, and R. J. Pomerantz.
1994. Potent inhibition of human immunodeficiency virus type 1 replication by an intracellular anti-Rev single-chain antibody. Proc. Natl. Acad. Sci. USA 91:5075-5079.

20. Duan, L.-X., and R. J. Pomerantz. 1994. Elimination of endogenous aberrant kappa chain transcription from $\mathrm{sp} 2 / 0$-derived hybridoma cells by specific ribozyme cleavage: utility in genetic therapy of HIV-1 infections. Nucleic Acids Res. 22:5433-5438.

21. Duan, L.-X., and R. J. Pomerantz. 1996. Intracellular antibodies for HIV-1 gene therapy. Sci. Med. 3:24-33

22. Duan, L.-X., H. Zhang, J. W. Oakes, O. Bagasra, and R. J. Pomerantz. 1994 Molecular and virological effects of intracellular anti-Rev single-chain variable fragments on the expression of various human immunodeficiency virus-1 strains. Hum. Gene Ther. 5:1315-1324.

23. Duan, L.-X., M. Zhu, O. Bagasra, and R. J. Pomerantz. 1995. Intracellular immunization against HIV-1 infection of human T-lymphocytes: utility of anti-Rev single-chain variable fragments. Hum. Gene Ther. 6:1561-1571.

24. Dyda, F., A. B. Hickman, T. M. Jenkins, A. Engelman, R. Craigie, and D. R. Davies. 1994. Crystal structure of the catalytic domain of HIV-1 integrase: similarity to other polynucleotidyl transferases. Science 266:1981-1986.

25. Elison, V., H. Abrams, T. Roe, J. Lifson, and P. Brown. 1990. Human immunodeficiency virus integration in a cell-free system. J. Virol. 64:27112715 .

26. Engelman, A., G. Englund, J. M. Orenstein, M. A. Martin, and R. Craigie. 1995. Multiple effects of mutations in human immunodeficiency virus type 1 integrase on viral replication. J. Virol. 69:2729-2736.

27. Engelman, A., A. B. Hickman, and R. Craigie. 1994. The core and carboxylterminal domains of the integrase protein of human immunodeficiency virus type 1 each contribute to nonspecific DNA binding. J. Virol. 68:5911-5917.

28. Engelman, A., K. Mizuuch, and R. Craigie. 1991. HIV-1 DNA integration: mechanism of viral DNA cleavage and DNA strand transfer. Cell 67:12111221.

29. Erice, A., and H. H. Balfour. 1994. Resistance of HIV-1 to anti-retroviral agents: a review. Clin. Infect. Dis. 18:149-156.

30. Farnet, C. M., and W. A. Haseltine. 1991. Determination of viral protein present in the human immunodeficiency virus type 1 preintegration complex. J. Virol. 65:1910-1915.

31. Feldherr, C. M., and D. Akin. 1994. Role of nuclear trafficking in regulating cellular activity. Int. Rev. Cytol. 151:183-228.

32. Gallay, P., S. Swingler, J. Song, F. Bushman, and D. Trono. 1995. HIV nuclear import is governed by the phosphotyrosine-mediated binding of matrix to the core domain of integrase. Cell 83:569-576.

33. Hirsch, M. S., and R. T. D’Aquila. 1993. Therapy for human immunodeficiency virus infection. N. Engl. J. Med. 328:1686-1695.

34. Holler, T. P., S. K. Foltin, Q.-Z. Ye, and D. J. Hupe. 1993. HIV-1 integrase expressed in E. coli from a synthetic gene. Gene 136:323-328.

35. Jenkins, T. M., A. Engelman, R. Ghirlando, and R. Craigie. 1996. A soluble active mutant of HIV-1 integrase. J. Biol. Chem. 271:7712-7713.

36. Katz, R. A., G. Merkel, J. Kulkosky, J. Leis, and A. M. Skalka. 1990. The avian retroviral IN protein is both necessary and sufficient for integrative recombination in vitro. Cell 63:87-95.

37. Katz, R. A., and A. M. Skalka. 1994. The retroviral enzymes. Annu. Rev. Biochem. 63:133-173.

38. Kubota, S., L. Duan, R. A. Furuta, M. Hatanaka, and R. J. Pomerantz. 1996 Nuclear preservation and cytoplasmic degradation of human immunodeficiency virus type $1 \mathrm{Rev}$ protein. J. Virol. 70:1282-1287.

39. Kulkosky, J., K. S. Jones, R. A. Katz, J. P. G. Mack, and A. M. Skalka. 1992 Residues critical for retroviral integrative recombination in a region that is highly conserved among retroviral/retrotransposon integrases and bacterial insertion sequence transposases. Mol. Cell. Biol. 12:2331-2338.

40. Kulkosky, J., R. A. Katz, and A. M. Skalka. 1990. Terminal nucleotides of the preintegrative linear form of HIV-1 DNA deduced from the sequence of circular DNA junctions. J. Acquired Immune Defic. Syndr. 3:852-858.

41. Kulkosky, J., and A. M. Skalka. 1994. Molecular mechanism of retroviral DNA integration. Pharmacol. Ther. 61:185-203.

42. Kwok, S., J. J. Lipka, N. McKinney, D. E. Kellog, B. J. Poiesz, S. K. H. Foung, and J. J. Sninsky. 1990. Low incidence of HTLV infections in random blood donors with indeterminate Western blot patterns. Transfusion 30:491-494.

42a.Levy, J. A. 1993. Pathogenesis of human immunodeficiency virus infection Microbiol. Rev. 57:183-289.

43. Levy-Mintz, P., L.-X. Duan, D. Bizub-Bender, J. Kulkosky, A. M. Skalka and R. J. Pomerantz. 1995. Anti-HIV-1 integrase single chain variable fragments (SFv) as tools for gene therapy. Presented at the Cold Spring Harbor Symposium on RNA Tumor Viruses, Cold Spring Harbor, N.Y., 26 May 1995.

44. Lisziewicz, J., D. Sun, D. Lisziewicz, and R. C. Gallo. 1995. Anti-tat gene therapy: a candidate for late-stage AIDS patients. Gene Ther. 2:218-222.

45. Liu, J., C. Woffendin, Z.-Y. Yang, and G. J. Nabel. 1994. Regulated expression of a dominant negative form of Rev improves resistance to HIV replication in T cells. Gene Ther. 1:32-37.

46. Lutzke, P., R. A. C. Vink, and R. H. A. Plasterk. 1994. Characterization of the 
minimal DNA-binding domains of the HIV integrase protein. Nucleic Acids Res. 22:4125-4131.

47. Maciejewski, J. P., F. F. Weichold, N. S. Young, A. Cara, D. Zella, M. S Reitz, Jr., and R. C. Gallo. 1995. Intracellular expression of antibody fragments directed against HIV reverse transcriptase prevents HIV infection in vitro. Nat. Med. 1:667-673.

48. Maniatis, T., E. F. Fritsch, and J. Sambrook. 1982. Molecular cloning: a laboratory manual. Cold Spring Harbor Laboratory Press, Cold Spring Harbor, N.Y.

49. Marasco, W. A., W. A. Haseltine, and I. S.-Y. Chen. 1993. Design, intracellular expression, and activity of a human anti-human immunodeficiency virus type 1 gp120 single-chain antibody. Proc. Natl. Acad. Sci. USA 90:78897893.

50. Marchuk, D., M. Drumm, A. Saulino, and F. S. Collins. 1990. Construction of T-vectors, a rapid and general system for direct cloning of unmodified PCR products. Nucleic Acids Res. 19:1154.

51. Masuda, T., V. Planelles, P. Krogstad, and I. S. Y. Chen. 1995. Genetic analysis of human immunodeficiency virus type 1 integrase and the U3 at site: unusual phenotype of mutants in the zinc finger-like domain. J. Virol. 69:6687-6696.

52. Mazumder, A., D. Cooney, R. Agbaria, M. Gupta, and Y. Pommier. 1994. Inhibition of human immunodeficiency virus type 1 integrase by $3^{\prime}$-azido-3'deoxythymidylate. Proc. Natl. Acad. Sci. USA 91:5771-5775.

53. Mhashilkar, A. B., J. Bagley, I. S.-Y. Chen, A. M. Szilvay, D. G. Helland, and W. A. Marasco. 1995. Inhibition of HIV-1 Tat-mediated LTR transactivation and HIV-1 infection by anti-Tat single chain antibodies. EMBO J. 14:15421551.

54. Miller, A. D., and G. J. Roseman. 1989. Improved retroviral vectors for gene transfer and expression. BioTechniques 7:980-990.

55. Pauza, C. D., and J. Galindo. 1989. Persistent human immunodeficiency virus type 1 infection of monoblastoid cells leads to accumulation of selfintegrated viral DNA and to production of defective virions. J. Virol. 63: 3700-3707.

55a.Pauza, C. D., P. Trivedi, T. S. Mckechnie, D. D. Richman, and F. M. Graziano. 1994. 2-LTR circular viral DNA as a marker for human immunodeficiency virus type 1 infection in vivo. Virology 205:470-478.

56. Pilkington, G. R., L.-X. Duan, M. H. Zhu, W. Kell, and R. J. Pomerantz. 1996. Recombinant human Fab antibody fragments to HIV-1 Rev and Tat regulatory proteins: direct selection from a phage library. Mol. Immunol. 33:439-449.

57. Poiesz, B. J., G. D. Ehrlich, B. C. Byrne, K. Wells, S. Kwok, and J. Sninsky. 1990. In L. M. de la Maza and E. M. Peterson (ed.), Medical virology, vol. 9. p. 47-75. Plenum Press, New York.

58. Pomerantz, R. J., and D. Trono. 1995. Genetic therapies for HIV infections: promise for the future. AIDS 9:985-993.

59. Pryciak, P. M., and H. E. Varmus. 1992. Nucleosomes, DNA-binding proteins, and DNA sequence modulate retroviral integration target site selection. Cell 69:769-780.

60. Scharfmann, R., J. H. Axelrod, and I. M. Verma. 1991. Long-term in vivo expression of retrovirus-mediated gene transfer in mouse fibroblast implants. Proc. Natl. Acad. Sci. USA 88:4626-4630.

61. Shaheen, F., L. Duan, M. Zhu, O. Bagasra, and R. J. Pomerantz. 1996. Targeting human immunodeficiency virus type 1 reverse transcriptase by intracellular expression of single-chain variable fragments to inhibit early stages of the viral life cycle. J. Virol. 70:3392-3400.

62. Sherman, P. A., M. L. Dickson, and J. A. Fyfe. 1992. Human immunodeficiency virus type 1 integration protein: DNA sequence requirements for cleaving and joining reactions. J. Virol. 66:3593-3601.

63. Siomi, H., H. Shida, M. Maki, and M. Hatanaka. 1990. Effects of a highly basic region of human immunodeficiency virus Tat protein on nucleolar localization. J. Virol. 64:1803-1807.

64. St. Clair, M. H., J. L. Martin, G. Tudor-Williams, M. C. Bach, C. L. Vavro, D. M. King, P. Kellam, S. D. Kemp, and B. A. Larder. 1991. Resistance to ddI and sensitivity to AZT induced by a mutation in HIV-1 reverse transcriptase. Science 253:1557-1559.

65. Studier, F. W., A. H. Rosenberg, J. J. Dunn, and J. W. Dubendorff. 1990. Use of T7 polymerase for direct expression of cloned genes. Methods Enzymol. 185:60-89.

66. Sun, L. Q., J. Pyati, J. Smythe, L. Wang, J. MacPherson, W. Gerlach, and G. Symonds. 1995. Resistance to human immunodeficiency virus type 1 infection conferred by transduction of human peripheral blood lymphocytes with ribozyme, antisense, or polymeric trans-activation response element constructs. Proc. Natl. Acad. Sci. USA 92:7272-7276.

67. Tai, M.-S., M. Mudgett-Hunter, D. Levinson, G.-M. Wu, E. Haber, H. Oppermann, and J. S. Huston. 1990. A bifunctional fusion protein containing Fc-binding fragment B of staphylococcal protein A amino terminal to antidigoxin single-chain Fv. Biochemistry 29:8024-8030.

68. Wu, Y., L. Duan, M. Zhu, B. Hu, S. Kubota, O. Bagasra, and R. J. Pomerantz. 1996. Binding of intracellular anti-Rev single chain variable fragments to different epitopes of human immunodeficiency virus type 1 Rev: variations in viral inhibition. J. Virol. 70:3290-3297.

69. Yu, M., J. Ojwang, O. Yamada, A. Hampel, J. Rapapport, D. Looney, and F Wong-Staal. 1993. A hairpin ribozyme inhibits expression of diverse strain of human immunodeficiency virus type 1. Proc. Natl. Acad. Sci. USA 90: 6340-6344.

70. Zhang, H., Y. Zhang, T. P. Spicer, M. A. Abbott, and B. J. Poiesz. 1993. Reverse transcription takes place within extracellular HIV-1 virions: potential biological significance. AIDS Res. Hum. Retroviruses 9:1287-1296. 